\title{
CORRECTION
}

\section{Correction to: Geometric modeling and torque analysis of the magnetic nutation gear drive}

\author{
Ding-jian Huang ${ }^{1,2} \cdot$ Li-gang Yao $^{1} \cdot$ Wen-jian $\mathrm{Li}^{1} \cdot$ Jun Zhang $^{1}$
}

Published online: 27 October 2017

(C) Springer-Verlag GmbH Deutschland 2017

\section{Correction to:}

Forsch Ingenieurwes 2017

https://doi.org/10.1007/s10010-017-0246-9

Due to an oversight the captions of Figs. 6 and 7 are incorrect.

The correct captions are given here.

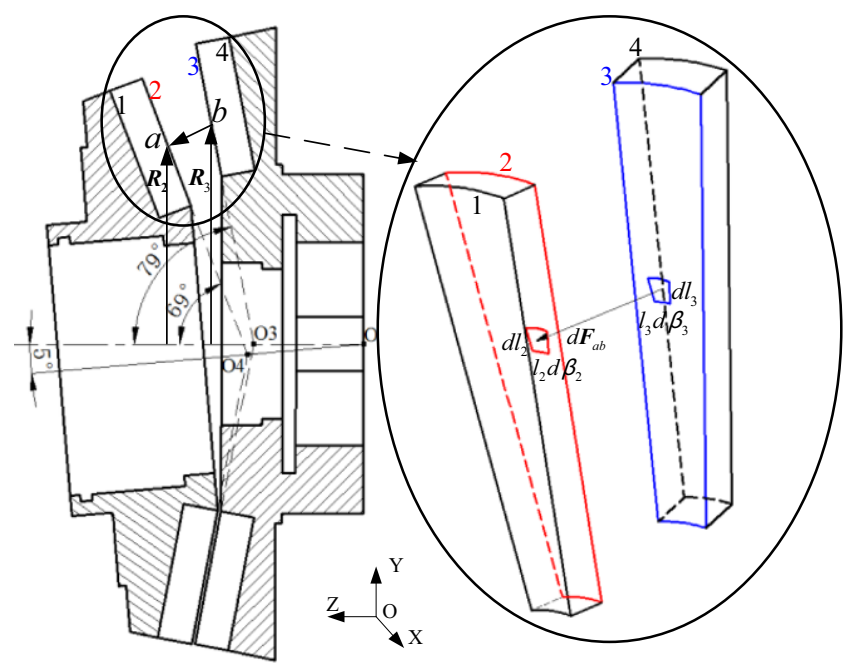

Fig. 6 Magnetic force between the 2 and the 3 surfaces

The online version of the original article can be found under https://doi.org/10.1007/s10010-017-0246-9.

\section{Ding-jian Huang \\ huangdjfzu@qq.com}

School of Mechanical Engineering and Automation, Fuzhou University, Fuzhou, China

2 School of Mechanical and Automotive Engineering, Fujian University of Technology, Fuzhou, China

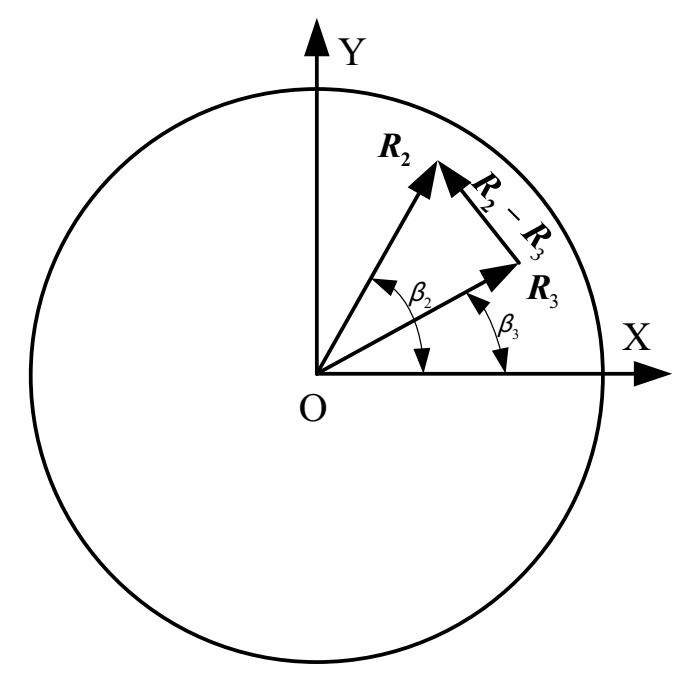

Fig. 7 Vectors $R_{2}$ and $R_{3}$ on the plane XOY 